\title{
Effect of Gas Bubbling on Tensile Elongation of Gravity Mold Castings of Magnesium Alloy
}

\author{
Chang Dong Yim ${ }^{1}$, Guohua $\mathrm{Wu}^{2}$ and Bong Sun You ${ }^{1}$ \\ ${ }^{1}$ Energy Materials Research Center, Korea Institute of Machinery and Materials, Sangnam 66 Changwon Gyeongnam, Korea \\ ${ }^{2}$ State Key Laboratory of Metal Matrix Composites, Shanghai Jiao Tong University, Shanghai 200030, P. R. China
}

\begin{abstract}
The effect of Ar gas bubbling on the tensile elongation of gravity mold castings of AZ91D magnesium alloy was evaluated qualitatively. The beneficial effect of gas bubbling on the tensile elongation of castings was resulted from the removal of inclusions in melt. The removal efficiency of inclusion by bubble floatation is dependent on processing variables including flow rate of gas, gas blowing time and melt temperature. Considering only the interaction between bubble and inclusion, the removal efficiency of inclusion will increase with increase in flow rate of gas, gas blowing time and melt temperature. But dissolution of gas into melt and entrance of new non-metallic particles formed on the melt surface deteriorated the tensile elongation of castings. [doi:10.2320/matertrans.MRP2007103]
\end{abstract}

(Received May 1, 2007; Accepted July 18, 2007; Published August 29, 2007)

Keywords: gas bubbles, tensile elongation, magnesium alloys, non-metallic inclusions, dissolution of gas

\section{Introduction}

Recently application of magnesium alloys is expanded rapidly over the whole industry, especially in automotive and electronic industries. Most of magnesium alloy parts are produced by casting process and the quality control of castings is very important to reliability and durability of parts. Various properties of magnesium alloy castings are deteriorated by defects such as non-metallic inclusion and pore. ${ }^{1-5)}$ Especially control of non-metallic inclusion remained in magnesium alloy castings is very important because the possibility of entrance of non-metallic inclusion into melt is very high due to high reactivity of magnesium alloy melt with gas species above melt surface. There are various methods for removal of inclusions in melt including addition of flux, gas bubbling and filtration. ${ }^{6-8)}$ Formerly a method of addition of flux was mainly applied to remove inclusions from magnesium alloy melt. ${ }^{9-11)}$ But part of flux was entered into melt during pouring when flux could not be entirely removed as dross and/or sludge before pouring and the flux remained in casting degraded the quality of castings as harmful defect. So a method of bubbling of inert gas into melt has been paid attention as new method for removal of inclusions from melt, especially during steelmaking. ${ }^{12-15)}$ But studies on removal of inclusions from magnesium alloy melt by gas bubbling have not been carried out actively. In this study the effect of Ar gas bubbling on the removal of inclusions from AZ91D magnesium alloy melt is evaluated indirectly by measurement of tensile elongation of gravity mold castings of AZ91D magnesium alloy and analyzed qualitatively.

\section{Experimental Procedure}

$6 \mathrm{~kg}$ of AZ91D magnesium alloy was charged into a low carbon steel crucible and heated to $983 \sim 1023 \mathrm{~K}$. A protective gas mixed of $0.5 \% \mathrm{SF}_{6}$ and $\mathrm{CO}_{2}$ was blown into the crucible at flow rate of $5 \mathrm{ml} \cdot \mathrm{s}^{-1}$ to prevent oxidation and ignition of ingot and melt during heating. After the melt temperature reached to a given temperature, a rotary impeller with nozzle

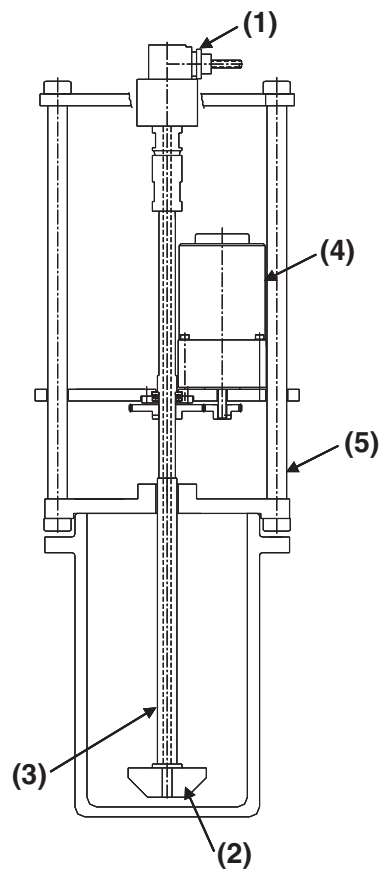

(1) Rotary Valve

(2) Impeller

(3) Steel Tube

(4) Motor

(5) Supporting Bar

Dimensions of System (unit: $\mathrm{mm}$ )

- Crucible: $\Phi 300$ x h 500

- Supporting Bar: $\Phi 15$ x h 700

- Steel Tube: $\Phi 10 \times \mathrm{h} 1000$

- Impeller: $\Phi 50 \times \mathrm{h} 20$

- Nozzle: $\Phi 0.2$

Fig. 1 Schematic drawing of gas blowing apparatus.

of $0.2 \mathrm{~mm}$ in diameter at lower part was inserted into the melt and then high purity Ar gas (99.99\%) was blown in the melt through the nozzle by using a gas blowing apparatus as shown in Fig. 1. The flow rate of Ar gas was changed from $8.33 \times 10^{-6} \mathrm{~m}^{3} \cdot \mathrm{s}^{-1}$ to $30.3 \times 10^{-6} \mathrm{~m}^{3} \cdot \mathrm{s}^{-1}$ and the blowing time was varied from $1800 \mathrm{~s}$ to $3600 \mathrm{~s}$. Dross at melt surface was skimmed out after completion of gas blowing and then the melt was poured into a low carbon steel mold preheated to $473 \mathrm{~K}$. Table 1 shows the experimental conditions of Ar gas bubbling.

Specimens for microstructure observation and tensile test were cut from the gravity mold castings at same position. The specimens for microstructure observation were mechanically polished by using emery papers of \#100 2400 and pastes containing diamond particles of $1 \mu \mathrm{m}$ diameter and then etched by using acetic picral solution $(10 \mathrm{~mL}$ acetic 
Table 1 Experimental conditions of Ar gas bubbling.

\begin{tabular}{cccc}
\hline No. & $\begin{array}{c}\text { Flow Rate of Gas } \\
\left(\mathrm{m}^{3} \cdot \mathrm{s}^{-1}\right)\end{array}$ & $\begin{array}{c}\text { Gas Blowing Time } \\
(\mathrm{s})\end{array}$ & $\begin{array}{c}\text { Melt Temperature } \\
(\mathrm{K})\end{array}$ \\
\hline 1 & $8.33 \times 10^{-6}$ & 1800 & 1003 \\
2 & $16.7 \times 10^{-6}$ & 1800 & 1003 \\
3 & $30.3 \times 10^{-6}$ & 1800 & 1003 \\
4 & $30.3 \times 10^{-6}$ & 2400 & 1003 \\
5 & $30.3 \times 10^{-6}$ & 3600 & 1003 \\
6 & $30.3 \times 10^{-6}$ & 1800 & 983 \\
7 & $30.3 \times 10^{-6}$ & 1800 & 1013 \\
8 & $30.3 \times 10^{-6}$ & 1800 & 1023 \\
\hline
\end{tabular}

acid $+4.2 \mathrm{~g}$ picric acid $+10 \mathrm{~mL}$ distilled water $+70 \mathrm{~mL}$ ethanol $(95 \%)$ ) in order to reveal the microstructure more distinctly. Subsize tensile specimens with gage length of $25 \mathrm{~mm}$, width of $6 \mathrm{~mm}$ and thickness of $3 \mathrm{~mm}$ were machined from the castings and tensile tests were carried out 3 times per each casting at an initial strain rate of $1 \times 10^{-3} \mathrm{~s}^{-1}$ according to ASTM E 8M-03. The tensile elongation was defined as average values of each test.

\section{Results and Discussion}

Figure 2 shows the melt surfaces before and after skimming out dross after completion of gas bubbling for $1800 \mathrm{~s}$ at flow rate of $30.3 \times 10^{-6} \mathrm{~m}^{3} \cdot \mathrm{s}^{-1}$. Non-metallic inclusions were effectively separated by floatation of bubble-inclusion adhesion to melt surface as shown in Fig. 2(a) and clean melt could be supplied into a mold as shown in Fig. 2(b) by skimming out dross on the surface.

Figure 3 shows the change of tensile elongation of gravity mold castings of AZ91D magnesium alloy with processing variables including flow rate of gas, blowing time and melt temperature. The tensile elongation was affected strongly by processing variables. The tensile elongation increased dramatically with increasing flow rate of gas as shown in Fig. 3(a). In castings produced with change of gas blowing time or melt temperature, it seemed that there were critical values of gas blowing time and melt temperature to maximize the effect of gas blowing and show the maximum tensile elongation as shown in Fig. 3(b) and Fig. 3(c). The tensile elongation increased explosively up to $1800 \mathrm{~s}$ of gas blowing time, but it decreased gradually when gas bubbling continued above $1800 \mathrm{~s}$. The tensile elongation also had the peak value when melt temperature was $1013 \mathrm{~K}$.

Wang et al. ${ }^{16)}$ suggested a model for inclusion removal efficiency by gas bubbling under assumptions as follows.

(1) Bubbles and inclusions all have certain size with uniform distribution in molten metal.

(2) Inclusions are only removed by bubble floatation.

(3) The size of bubbles is independent of flow rate of gas.

According to the above model, the percentage removal efficiency of inclusion at time $\mathrm{t}$ can be described as:

$$
\begin{aligned}
\eta & =\left(1-e^{-k t}\right) \times 100 \% \\
k & =\frac{3 T_{l} h P Q_{g}}{2 T_{g} V_{l} D_{b}}
\end{aligned}
$$

where $T_{l}, T_{g}, h, V_{l}, P, Q_{g}$ and $D_{b}$ are melt temperature, temperature of gas in nozzle, height of melt bath, volume of melt, total attachment probability, flow rate of gas and bubble size, respectively.

According to a previous study, ${ }^{17)}$ the size of bubbles did not change with flow rate of gas when flow rate of gas was below $40 \times 10^{-6} \mathrm{~m}^{3} \cdot \mathrm{s}^{-1}$. In this study, flow rate of gas was changed from $8.33 \times 10^{-6} \mathrm{~m}^{3} \cdot \mathrm{s}^{-1}$ to $30.3 \times 10^{-6} \mathrm{~m}^{3} \cdot \mathrm{s}^{-1}$. So it is reasonable to assume that the size of bubble is independent of flow rate of gas under the bubbling conditions used in this study. From eq. (1) and eq. (2), the percentage removal efficiency of inclusion increases with increase in flow rate of gas.

Tensile elongation of castings is affected by pores as well as inclusions. The pores in castings are formed mainly by gas remained in melt and shrinkage during solidification. Assuming that the amount of pores formed by shrinkage was constant under the gas bubbling and casting conditions used in this study, the amount of pores in castings would be changed mainly by gas content remained in melt. The amount of gas blown into melt per unit time increases by increase in flow rate of gas, which will be resulted in increase of gas dissolved in melt. As mentioned above, the tensile elongation of castings is dependent on the total amount of inclusions and

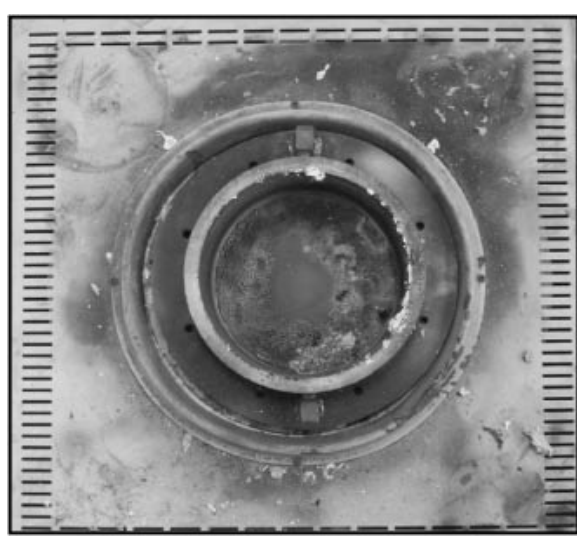

(a)

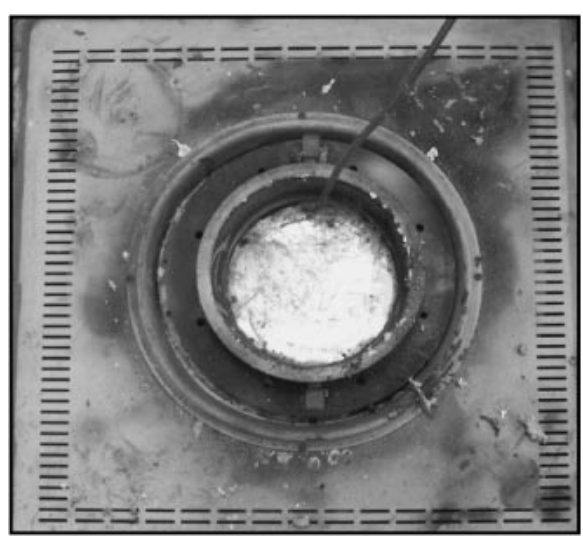

(b)

Fig. 2 Photographs of melt surfaces before and after skimming out dross after completion of gas bubbling; (a) before skimming (b) after skimming. 


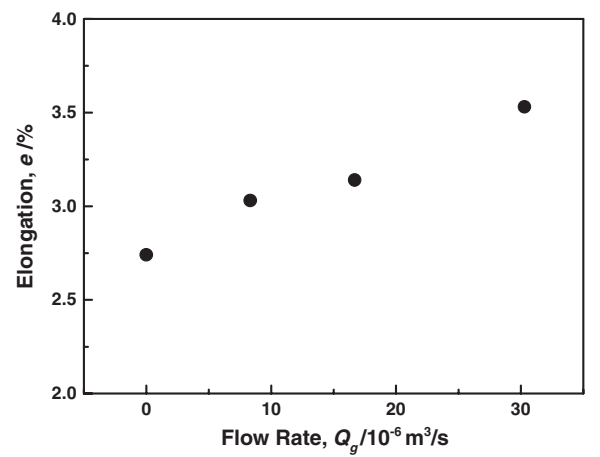

(a)

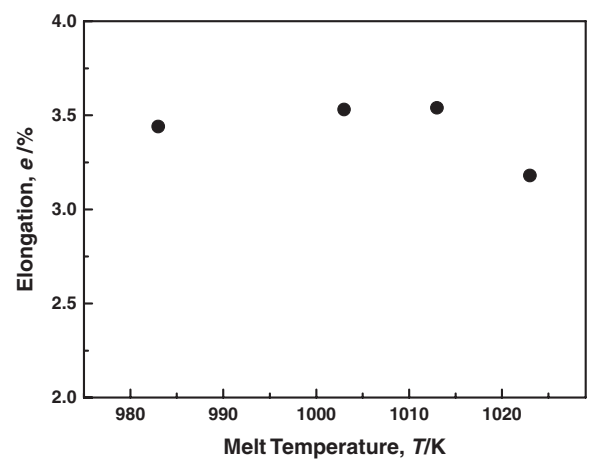

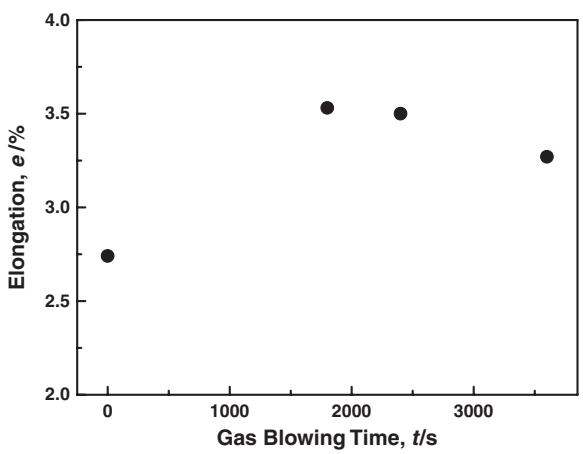

(b)

(c)

Fig. 3 Tensile elongations of gravity mold castings of AZ91D magnesium alloy produced with change of; (a) flow rate of gas (b) gas blowing time (c) melt temperature.

pores. With increase in flow rate of gas, the amount of inclusions decreases due to higher removal efficiency but the amount of pores formed by remained gas increases. It seemed that the amount of deteriorate defects including inclusions and pores would decrease with increase in flow rate of gas due to more effective removal of inclusions compared to pore formation under gas blowing conditions used in this study as shown in increase of tensile elongation of Fig. 3(a).

According to eq. (1), the percentage removal efficiency of inclusion increases with increase in bubbling time and then the tensile elongation of castings will increase if gas bubbling will not affect the tensile elongation by another way except removal of inclusion. But the tensile elongation of castings produced in the condition of bubbling time of $1800 \mathrm{~s}$ was the highest and extended bubbling above $1800 \mathrm{~s}$ deteriorated the tensile elongation of castings as shown in Fig. 3(b). This degradation in tensile elongation was resulted from the dissolved gas in melt. The molten metal has solubility of gas to some degree. Most of gas blown into melt will be floated to melt surface as bubble but some of gas will be dissolved in melt due to solubility of gas in melt. The dissolved gas in melt acts as a source of pores in castings. The tensile elongation of castings produced in the condition of short bubbling time will increase with bubbling time due to decrease in inclusions although some defects originated from the dissolved gas will be remained in castings. When most of inclusions in melt will be removed by bubble floatation, the tensile elongation of castings will decrease mainly by the remained gas pore. The amount of the dissolved gas in melt increases with increase in bubbling time if the melt will not be saturated by gas for given bubbling time, which is resulted in the decrease in the tensile elongation of castings produced in the condition of longer bubbling time as shown in Fig. 3(b).

Viscosity of melt decreases with increase in melt temperature and then floatation velocity of bubble increases, ${ }^{18)}$ which is resulted in increase in the percentage removal efficiency of inclusion predicted from eq. (1) and eq. (2). But the reactivity of magnesium alloy melt is very high and new non-metallic particles are created by reaction between melt and gas above melt surface and are entered into melt. So the amount of inclusions in melt is dependent on the removal of inclusion from melt by bubble floatation and entrance of new non-metallic particles into melt by melt-gas reaction. It was reported that $\mathrm{MgO}$ and $\mathrm{MgF}_{2}$ were mainly formed by reaction between magnesium and gas on melt surface and fluorine was supplied by decomposition of $\mathrm{SF}_{6} \cdot{ }^{19)}$ As melt temperature increases, the decomposition of $\mathrm{SF}_{6}$ will occur more actively ${ }^{20)}$ and the amount of $\mathrm{MgF}_{2}$ formed by reaction between magnesium and fluorine will increase. The amount of inclusion remained in melt will decrease when the increase of the amount of inclusion removed by bubble floatation due to increase in melt temperature will be larger than the increase of amount of new inclusion entered into melt. But, if the amount of new inclusion will exceed the amount of inclusion removed by bubble floatation above a certain temperature, more inclusions will be remained in melt with increase in melt temperature. The content of gas remained in melt also increases with increase in melt temperature due to higher solubility, which is resulted in more pores in castings. 


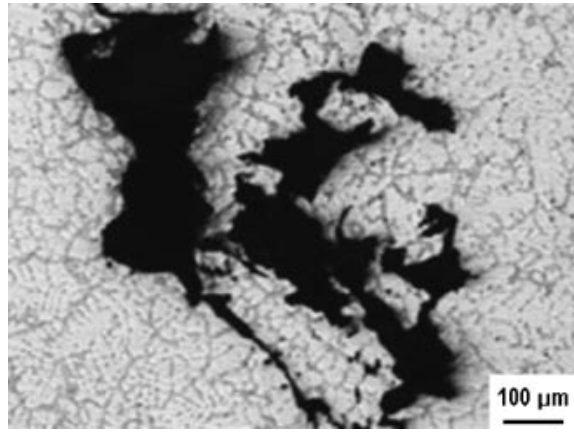

(a)

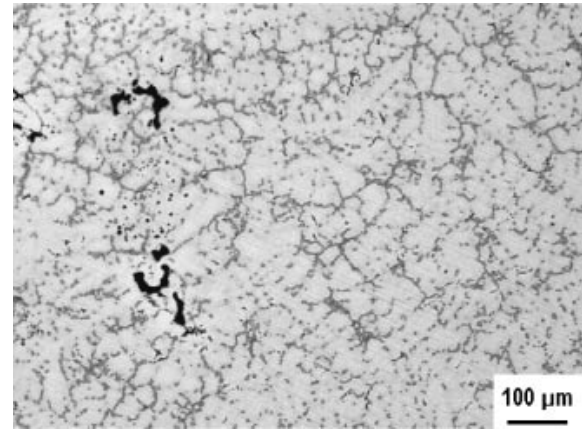

(b)

Fig. 4 Microstructures of gravity mold castings of AZ91D magnesium alloys; (a) no gas bubbling (b) gas bubbling for $1800 \mathrm{~s}$ at flow rate of $30.3 \times 10^{-6} \mathrm{~m}^{3} \cdot \mathrm{s}^{-1}$.

So castings will have a peak value of tensile elongation at a certain temperature at which the total amount of defects including inclusions and pores will be minimized and then the tensile elongation of castings will decrease with increase in melt temperature as shown in Fig. 3(c).

Figure 4(a) shows the microstructure of gravity mold casting of AZ91D magnesium alloy not treated by gas bubbling. A large black region of inclusion and/or gas pore was observed which would deteriorate the tensile elongation of castings. On the other hand, the size of black region decreased dramatically in case of castings refined by gas bubbling as shown in Fig. 4(b). Although most of inclusions could be removed by adhesion with bubbles, some of new inclusions entered into melt would be remained in melt and part of gas blown into melt would be dissolved into melt instead of floating to surface, which would act as a source of volume defect observed as black region in castings. So smaller black region was also observed in the castings refined by gas bubbling.

\section{Conclusion}

In summary, the most beneficial effect of gas bubbling is the removal of inclusion in melt which deteriorates the tensile elongation of castings. The removal efficiency of inclusion by bubble floatation is dependent on processing variables including flow rate of gas, gas blowing time and melt temperature. Considering only the interaction between bubble and inclusion, the removal efficiency of inclusion will increase with increase in flow rate of gas, gas blowing time and melt temperature according to eq. (1) and eq. (2). But bubble generated from nozzle also interacts with melt and some of gas is dissolved into melt to some degree. The dissolved gas acts as a source of pores in castings, which deteriorates the tensile elongation. The new non-metallic particles are formed by reaction between melt and gas above melt surface and these particles are entered into melt during gas bubbling. The amount of new inclusion entered into melt increases with increase in melt temperature and it exceeds the amount of inclusion removed by bubble floatation above a certain temperature, which is resulted in decrease in the tensile elongation of castings. So the condition of gas bubbling should be optimized in order to produce the castings with excellent tensile elongation.

\section{Acknowledgements}

This study was financially supported by Korean Ministry of Commerce, Industry and Energy through Energy Technology R\&D Program.

\section{REFERENCES}

1) T. Kinzler and F. Klein: Metall. 52 (1998) 716-720.

2) A. K. Dahle, S. Sannes, D. H. St John and H. Westengen: J. Light Met. 1 (2001) 99-103.

3) H. Mayer, M. Papakyriacou, B. Zettl and S. E. Stanzl-Tschegg: Inter. J. Fatigue 25 (2003) 245-256.

4) J. P. Weiler, J. T. Wood, R. J. Klassen, E. Maire, R. Berkmortel and G. Wang: Mater. Sci. Eng. A 395 (2005) 315-322.

5) C. D. Lee: Met. Mater. Inter. 12 (2006) 377-383.

6) K. Yamada, T. Watanabe, K. Fukuda, T. Kawaragi and T. Tashiro: Trans. Iron and Steel Inst. Jpn. 27 (1987) 873-877.

7) S. B. Singh and A. K. Chakrabarti: Ironmaking and Steelmaking 20 (1993) 442-444.

8) L. Zhang, J. Aoki and B. G. Thomas: Metall. Mater. Trans. B 37 (2006) 361-379.

9) H. Gao, G. Wu, W. Ding and Y. Zhu: J. Mater. Sci. 39 (2004) 64496456.

10) H. Gao, G. Wu, W. Ding and Y. Zhu: Trans. Nonferrous Met. Soc. China 14 (2004) 530-536.

11) G. Wu, H. Gao, Y. Zhu and W. Ding: Acta Metall. Sinica 40 (2004) 694-698.

12) J.-S. Cho and H.-G. Lee: ISIJ Inter. 41 (2001) 151-157.

13) L. Zhang, J. Aoki and B. G. Thomas: Mater. Sci. Tech. 2 (2004) 161177.

14) J. P. Rogler, L. J. Heaslip and M. Mehrvar: Canadian Metall. Quar. 44 (2005) 357-368.

15) L. T. Wang, S. H. Peng, Q. Y. Zhang and Z. B. Li: Steel Res. Inter. 77 (2006) 25-31.

16) L. T. Wang, Q. Y. Zhang, C. H. Deng and Z. B. Li: ISIJ Inter. 45 (2005) 1138-1144.

17) K. Mori, M. Sano and T. Sato: Trans. Iron and Steel Inst. Jpn. 19 (1979) $553-558$.

18) L. Zhang and S. Taniguchi: Inter. Mater. Rev. 45 (2000) 59-82.

19) S. P. Cashion, N. J. Ricketts and P. C. Hayes: J. Light Met. 2 (2002) 4347.

20) S. Yasui, T. Amakawa, Y. Shirai, M. Nunokawa, M. Shibuya and K. Arai: Kagaku Kogaku Ronbunshu. 30 (2004) 194-199. 